\title{
Outros sujeitos : trabalhadores e associativismo negro nos mundos do trabalho
}

\author{
Jonatas Roque Ribeiro \\ Doutorando em História pela Universidade Estadual de Campinas (Unicamp)
}

\section{Resumo}

A história social do trabalho produzida no Brasil tem passado por importantes transformações nos últimos anos. Uma das promessas dessa renovação historiográfica é a inclusão dos trabalhadores negros na história social do trabalho. Trata-se de uma questão que vem sendo enfatizada por diversos autores nos últimos anos e alguns têm ido além da mera defesa dessa concepção, denunciando e chamando a atenção, justamente, para como os trabalhadores negros principalmente durante a vigência da escravidão - continuam excluídos da história do trabalho. Deste modo, o objetivo do artigo é rever as interpretaçóes tradicionais que postulam uma separação radical entre a história da escravidão e da liberdade e a história do trabalho, de modo a relacionar a experiência dos trabalhadores negros (escravizados, libertos e livres) com a dos trabalhadores ditos “livres” durante as últimas décadas da escravidão e no pós-abolição. Por fim, o texto aponta o papel do associativismo negro nos mundos do trabalho e as possibilidades investigativas que essa experiência social pode colocar ao campo temático.

Palavras-chave Historiografia do trabalho - Trabalhadores negros - Associativismo negro.

\section{Abstract}

The labor history produced in Brazil has undergone important changes in recent years. One of the promises of this historiographic renewal is the inclusion of black workers in the labor history. It is an issue that has been emphasized by several authors in recent years and some have gone beyond the mere defense of this conception, denouncing and calling attention, precisely, to how black workers - especially during the period of slavery - remain excluded of labor history. Thus, the objective of this article is to review the traditional interpretations that postulate a radical separation between the history of slavery and freedom and the labor history, in order to relate the experience of black workers (enslaved, freed and free) with that of the so-called "free" workers during the last decades of slavery and post-abolition. Finally, the text points out the role of black associations in the worlds of work and the investigative possibilities that this social experience can place in the thematic field.

Keywords Labor History - Black Workers - Black Associativism.

\section{Submissão}

$13 / 03 / 2020$

\section{Aprovação}

$\mathrm{I} 3 / 07 / 2020$
Publicação

$28 / \mathrm{II} / 2020$ 


\section{Introdução}

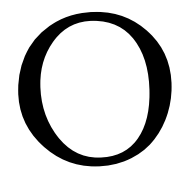

objetivo deste artigo é fazer, inicialmente, um pequeno balanço considerando alguns estudos da historiografia do trabalho que tiveram os trabalhadores negros e o associativismo negro como tema central, ou que de alguma forma propuseram questões relevantes para o desenvolvimento dessas temáticas. Primeiro, acuso o caráter arbitrário da seleção e, evidentemente, o risco das omissões, assumindo a parcialidade do balanço proposto com base naquilo que julguei como mais significativo e expressivo das pesquisas desenvolvidas em relação ao debate em tela. Segundo, procuro apontar ao longo do texto algumas possibilidades de análise e discussão para novas abordagens sobre o tema.

A história social do trabalho e dos trabalhadores produzida no Brasil tem passado por importantes transformações nas últimas décadas. Caminhos, abordagens, influências, diversidade na utilização de fontes, correntes e definições teóricas distintas tem marcado essa renovação do campo de estudos. Houve um redimensionamento nessa produção acadêmica, marcado pela atenção às ações de sujeitos históricos específicos, pela valorização da análise dos conflitos e embates entre os diversos grupos sociais e pela investigação das complexidades internas às classes, às tradições e outros aspectos que formaram, ao longo do tempo, a cultura dos trabalhadores. Temas tradicionais da história do Brasil, como escravidão e liberdade, imigração, e formas de organização e sociabilidade dos trabalhadores, por exemplo, ganharam novos contornos e novas formas de abordagem. As pesquisas sobre os operários e os trabalhadores assalariados urbanos ultrapassam os limites das análises que identificavam o tema às condições do trabalho fabril e ao desenvolvimento de sindicatos e partidos políticos. Deixando de lado as balizas cronológicas que tradicionalmente circunscreviam a experiência operária dos trabalhadores às décadas posteriores a 1930, esses novos estudos se voltaram também para o século XIX.'

Apesar dos inegáveis avanços, alguns temas continuam pouco explorados nesse campo de estudos. É o caso da história dos trabalhadores negros (escravizados, libertos e

\footnotetext{
Sobre os balanços e panoramas da história do trabalho no Brasil ver: GOMES, A. C. "Questão social e historiografia no Brasil do pós-1980: notas para um debate”. In: Estudos Históricos, vol. 2, n. 34, p. 157-186, 2004. BATALHA, C. "Os desafios atuais da história do trabalho". In: Anos 9o, vol. I3, n. 23/24, p. 87-104, 2006. NEGRO, A. L.; GOMES, F. "Além de senzalas e fábricas: uma história social do trabalho". In: Tempo Social, vol. I8, n. I, p. 217-240, 2006. CHALHOUB, S. e SILVA, F. T. "Sujeitos no imaginário acadêmico: escravos e trabalhadores na historiografia brasileira desde os anos 1980". In: Cadernos AEL, vol. I4, n. 26, p. I545, 2009. PETERSEN, S. "Repensar a história do trabalho". In: Espaço Plural, vol. I7, n. 34, p. 13-36, 2016. POPINIGIS, F.; TERRA, P. C. "Classe, raça e a história social do trabalho no Brasil (200I-2016)". In: Revista Estudos Históricos, vol. 32, n. 66, p. 307-329, 2019.
}

II6 • ano XI, n. I6, 2020 • ISSN 2I79-5487 
livres) e das suas formas de organização. Desde o pioneiro ensaio da historiadora Silvia Lara, "Escravidão, cidadania e história do trabalho", publicado em 1998, até o provocativo artigo do historiador Álvaro Nascimento, "Trabalhadores negros e o paradigma da ausência”, de 2016, a questão foi debatida e se denunciou a exclusão e invisibilidade dos sujeitos negros na produção historiográfica sobre os mundos do trabalho. ${ }^{2}$ Os autores apontaram os vários problemas trazidos pela ausência desses sujeitos históricos nos estudos da história social do trabalho e sugeriram alguns caminhos metodológicos para superá-los. ${ }^{3}$

Esses artigos e seus autores caminham na fronteira, ainda sólida, entre dois campos de estudos - a história dos trabalhadores negros (estudados quase que exclusivamente no âmbito da historiografia da escravidão) e a história dos trabalhadores livres e/ou assalariados (reduto ainda restrito da historiografia do trabalho) - temas que, timidamente, estão se aproximando e se fazendo presente nos estudos da história da escravidão e da história do trabalho. Nessa perspectiva, vários esforços têm sido feitos no sentido de derrubar o "muro de Berlim" historiográfico, expressão cunhada pelos historiadores Sidney Chalhoub e Fernando Teixeira da Silva, "que ainda emperra o diálogo necessário entre os historiadores da escravidão e os estudiosos das práticas políticas e culturais dos trabalhadores urbanos pobres e do movimento operário". ${ }^{4}$

Desde pelo menos a década de 1970, tanto a história da escravidão, como a história do trabalho passaram por importantes transformações, multiplicando seus temas e adensando suas abordagens. Essas mudanças, entre outros fatores, foram resultado da renovação do campo marxista que, sob a inspiração principalmente da produção inglesa, em especial da obra do historiador Edward P. Thompson, colocou a história dos trabalhadores em primeiro plano. ${ }^{5}$ Nos estudos sobre a escravidão, as pesquisas se voltaram para o cotidiano, costumes, resistências, acomodações, solidariedades e

2 LARA, S. H. "Escravidão, cidadania e história do trabalho no Brasil”. In: Revista Projeto História, n. 16, 1998. NASCIMENTO, A. “Trabalhadores negros e o 'paradigma da ausência': contribuições à história social do trabalho no Brasil”. In: Estudos Históricos, vol. 29, n. 59, p. 607-626, set/dez. 2016.

3 É preciso enfatizar, entretanto, que alguns poucos estudos analisaram as complexidades políticas, econômicas, culturais, sociais, étnicas e raciais que marcaram os mundos do trabalho no século XIX e no pós-abolição a partir da experiência de trabalhadores negros. Ver entre outros: CRUZ, M. C. V. Virando o jogo: estivadores e carregadores no Rio de Janeiro da Primeira República. 1998. 288 f. Tese (Doutorado) - Faculdade de Filosofia, Letras e Ciências Humanas, Universidade de São Paulo, São Paulo, 1998. MATTOS, M. B. Escravizados e livres: experiências comuns na formação da classe trabalhadora carioca. Rio de Janeiro: Bom Texto, 2008. CASTELLUCCI, A. "Classe e cor na formação do Centro Operário da Bahia (I890-1930)". In: Afro-Asia, n. 4I, p. 85-131, 20ı. SOUZA, R. Tudo pelo trabalho livre!: trabalhadores e conflitos no pós-abolição (Bahia, I892-1909). Salvador: Editora da UFBA, 20II. MAC CORD, M. Artifices da cidadania: mutualismo, educação e trabalho no Recife oitocentista. Campinas: Editora da UNICAMP, 20I2. SOUZA, R. Trabalbadores dos trilhos: imigrantes e nacionais livres, libertos e escravos na construção da primeira ferrovia baiana (1858-1863). Campinas: Editora da UNICAMP, 20I5. LONER, B. Construção de classe: operários de Pelotas e Rio Grande. $2^{\circ}$ ed. Pelotas: Ed. UFPel, 2016. 


\section{REVISTA ANGELUS NOVUS}

experiências de vida dos escravizados. Procurou-se, insistentemente, incorporar as visões escravas da escravidão e os significados de liberdade, trabalho, família, sociedade, entre outros, para homens e mulheres escravizados. ${ }^{6} \mathrm{~A}$ história do trabalho, por outro lado, cruzou os limites das análises que circunscreviam o tema ao trabalho fabril e à formação de sindicatos e partidos políticos. Tal historiografia passou a lidar com novos problemas e interpretações. Entre os vários "novos” temas se destacaram a cultura política dos trabalhadores, circulação de ideias, imigração, militância e formas de organização e de sociabilidade, greves e protestos, repressão, imprensa operária, cotidiano dos trabalhadores fora das fábricas e suas práticas culturais. ${ }^{7}$

Como desdobramento dessas questões, o conceito tradicional de classe foi questionado. $\mathrm{Na}$ história do trabalho, esse termo foi pensado, durante muito tempo, como um bloco homogêneo que abarcava, quase que exclusivamente, a experiência de trabalhadores (preferencialmente os operários fabris) assalariados, do sexo masculino, brancos e frequentemente de origem europeia. Isso teve muito a ver com uma questão de vocabulário. Segundo o historiador Marcelo Badaró Mattos, "nas línguas neolatinas, tendemos muitas vezes a traduzir equivocadamente a expressão alemã empregada por Karl Marx Arbeiterklasse, ou o correlato inglês working class, ou o termo francês classe ouvrière por classe operária", limitando, assim, o conceito à ideia de trabalho assalariado urbano e fabril. ${ }^{8}$ Esses conceitos, entretanto, tiveram significados distintos e amplos. $\mathrm{Na}$ Inglaterra, por exemplo, desde o início do século XIX, o termo "working classes" - na tradução literal "classes trabalhadoras" - foi amplamente utilizado "num sentido semelhante ao do uso do francês para designar o conjunto de trabalhadores pobres em suas diversas categorias profissionais" não se restringindo ao emprego do termo numa definição muito restritiva. "Na língua alemã não há expressão equivalente. Marx, por

5 A principal referência aqui é sem dúvida: THOMPSON, E. A formação da classe operária inglesa. Trad. Renato Busatto Neto; Cláudia Rocha de Almeida. Rio de Janeiro: Paz e Terra, 1987. 3v.

6 A bibliografia aqui é vasta e variada. Entre outros, conferir: LARA, S. H. Campos da violência: escravos e senhores na Capitania do Rio de Janeiro: 1750-I808. Rio de Janeiro: Paz e Terra, 1988. REIS, J. J.; SILVA, E. (Orgs.). Escravidão e invenção da liberdade: estudos sobre o negro no Brasil. São Paulo: Brasiliense; Rio de Janeiro: CNPq, 1988. CHALHOUB, S. Visóes da liberdade: uma história das últimas décadas da escravidão na corte. São Paulo: Companhia das Letras, 1990. MACHADO, M. H. P. T. O plano e o pânico: os movimentos sociais na década da Abolição. São Paulo: EDUSP; Rio de Janeiro: Editora UFRJ, 1994. SLENES, R. Na senzala, uma flor: esperanças e recordações na formação da família escrava: Brasil Sudeste, século XIX. Rio de Janeiro: Nova Fronteira, 1999. MATTOS, H. Das cores do silêncio: os significados da liberdade no sudeste escravista: Brasil, século XIX. Rio de Janeiro: Arquivo Nacional, 1995.

7 Para um balanço da produção e dos debates sobre a história do trabalho a partir dos anos 1970 ver a nota de rodapé $\mathrm{I}$.

8 MATTOS, M. B. "A classe trabalhadora: uma abordagem contemporânea à luz do materialismo histórico". In: Revista Outubro, vol. 2I, p. 8I-II7, 2013, p. 89.

II8 • ano XI, n. 16, 2020 • ISSN 2179-5487 
exemplo, utilizava expressóes que podemos traduzir literalmente como 'classe trabalhadora' ou 'proletariado'”. 9

Nesse movimento, há um esforço por “reconceitualizar a classe” pelos historiadores, como observou Marcelo Badaró Mattos. E isso inclui a necessidade de problematizar uma concepção demasiado estreita do que venha a ser a "classe”. Deriva daí "outras confusões vocabulares que precisam ser mencionadas quando são traduzidos conceitos e reflexões sobre trabalho e classe". "Partindo do idioma inglês", por exemplo, “'labour' ('labor' na grafia estadunidense) e 'work' são palavras normalmente traduzidas em português como 'trabalho', embora tenham na origem significados distintos":

"Labor" acabou por definir não apenas o "trabalho que cria valor", mas também serviu para identificar os movimentos sociais e políticos da classe trabalhadora (...). Já "work" definiu o trabalho na sua forma típica no capitalismo, trabalho assalariado, abstrato, assim, como movimentos e organizaçóes tradicionais [sindicatos e partidos políticos, por exemplo] da classe trabalhadora assalariada. ${ }^{10}$

Esses equívocos, a princípio simples questão de vocabulário, podem ser decisivos no modo como foi (e está sendo) construída narrativas e interpretações na historiografia do trabalho e na história da escravidão no Brasil. Por exemplo, quando se trata dos trabalhadores pobres - mas, neste grupo, especialmente os negros -, esse conceito tradicional de classe consegue ser oportuno? Ou seja, ele abarca a complexidade e a diversidade das experiências desses sujeitos? Nas últimas décadas, parcela da história social do trabalho e da historiografia da escravidão tem elaborado debates sobre a dimensão histórica do conceito de "classe trabalhadora". A proposição de "classe dos trabalhadores subalternos” do historiador Marcel van der Linden e a definição de "proletariado atlântico" dos historiadores Peter Linebaugh e Marcus Rediker, por exemplo, são aportes importantes na direção de uma leitura ampliada do conceito de classe." Guardadas as devidas diferenças entre os dois estudos, "seu ponto forte é

9 MATTOS, M. B. A classe trabalbadora: de Marx ao nosso tempo. São Paulo: Boitempo, 2019, p. 22-23.

Io MATTOS, M. B. A classe trabalhadora: de Marx ao nosso tempo, op. cit., p. 24.

II LINDEN, M. Trabalhadores do mundo: ensaios para uma história global do trabalho. Trad. Patrícia de Queiróz Carvalho Zimbres. Campinas: Editora da UNICAMP, 20I3. LINEBAUGH, P.; REDIKER, M. $A$ bidra de muitas cabeças: marinheiros, escravos, plebeus e a história oculta do Atlântico revolucionário. Trad. Berilo Vargas. São Paulo: Companhia das Letras, 2008. O conceito de classes/grupos subalternos foi analisado de forma pioneira pelo filósofo italiano Antônio Gramsci. Seu objetivo foi propor uma ampliação do significado histórico de classe trabalhadora, de forma a captar e integrar os grupos/movimentos das classes exploradas, dos oprimidos e dos marginalizados. GRAMSCI, A. Cadernos do cárcere, vol. I. Edição e trad. Carlos Nelson Coutinho. Rio de Janeiro: Civilização Brasileira, 1999, especialmente o Caderno II. Também o sociólogo Ricardo Antunes na tentativa de ampliar o conceito de classe trabalhadora, apresentou o termo "classe-que-vive-do-trabalho". Sua ideia foi construir uma noção ampliada de classe trabalhadora que fosse capaz de incluir "a totalidade daqueles que vendem sua força de trabalho". ANTUNES, R. Os sentidos do trabalho: ensaio sobre a afirmação e a negação do trabalho. São Paulo: Boitempo, 1999, p. IOI-IO4. 


\title{
REVISTA ANGELUS NOVUS
}

justamente o reconhecimento de que, de um ponto de vista transnacional, o capitalismo em formação desde o processo de expansão colonial do século XVI subjugou grupos diferenciados de trabalhadoras e trabalhadores, a partir de diferentes formas de exploração do trabalho". Esse pode ser “um caminho frutífero para encarar o potencial emancipatório do conjunto de trabalhadoras e trabalhadores submetidos à exploração pelo capital". ${ }^{22}$ Nesse caminho, é fundamental um investimento mais comprometido no diálogo entre os pesquisadores da história da escravidão e os da história do trabalho, assim como observou o historiador Álvaro Nascimento:

\begin{abstract}
Procurar entender as abordagens teóricas e metodológicas presentes em textos clássicos e recentes sobre escravidão e racismo, de um lado, e o cotidiano e lutas dos trabalhadores, de outro, passando ainda pelas relações de gênero, representa um exercício transitório para a consolidação de uma história social do trabalho vibrante, perceptível enquanto processo histórico. Ultrapassaremos, assim, a empobrecedora linearidade intercalada por cirúrgicos acontecimentos, que interrompem abruptamente os passos do homem no tempo e reforçam o ainda imponente muro de Berlim historiográfico descrito por Chalhoub e Silva. ${ }^{13}$
\end{abstract}

\section{Caminhos a percorrer e relações possíveis}

Em relação aos trabalhadores negros identificou-se que a história do trabalho tem muito mais desafios e investimentos a serem enfrentados do que a história da escravidão, apesar de reconhecermos que, nos últimos anos, tornou-se necessário fazer paralelos que auxiliem na aproximação dessas duas áreas de estudos. Mais recentemente, uma vertente da história do trabalho passou a apontar que trabalhadores negros e brancos conviveram tanto nas fábricas quanto nas ruas, além de terem partilhado outros espaços, como moradia, lazer, associações de cunho beneficente, etc., mas pouco se falou de outros espaços associativos nos quais esses sujeitos estiveram presentes, na própria trajetória de militantes e trabalhadores negros, nos conceitos históricos de cor, raça e racismo nos mundos do trabalho. A própria categoria "mundos do trabalho" no século XIX ainda é muito vaga e pouco trabalhada por essa historiografia..$^{14}$

I2 MATTOS, M. B. A classe trabalhadora: de Marx ao nosso tempo, op. cit., p. I33, I4I.

I3 NASCIMENTO, A. "Trabalhadores negros e o paradigma da ausência”, op. cit., p. 62I.

I4 Uma exceção nessa perspectiva é o trabalho de: MAC CORD, M. Artifices da cidadania, op. cit. Ver também: MAC CORD, M.; BATALHA, C. (Orgs.). Organizar e proteger: trabalhadores, associações e mutualismo no Brasil. Campinas: Editora da UNICAMP, 2014.

$\mathrm{I} 2 \mathrm{O} \cdot$ ano XI, n. $16,2020 \cdot \mathrm{ISSN} 2179-5487$ 
A atenção à experiência dos trabalhadores negros nos mundos do trabalho oitocentista tem revigorado, por exemplo, a historiografia sobre a escravidão, principalmente no estudo de temas como a experiência de liberdade em contextos nos quais vigoraram processos constantes de escravização e reescravização, as formas e relações de trabalho (formal, informal, escravo, forçado, livre, compulsório, contratual, masculino, feminino, infantil) e quanto às maneiras de garantir e defender a difusão dessas "formas" de trabalho num contexto de expansão do trabalho dito "livre" ao longo do século XIX.is Esse eixo de investigação - mundos do trabalho no século XIX pode ser bastante profícuo para articular temas de investigação e problemas de pesquisa fundamentais tanto para a história da escravidão como para a história do trabalho.

A discussão acerca dos limites difusos entre escravidão e liberdade tem raízes fincadas na questão do trabalho, que persiste sendo um eixo fundamental para compreender as relações sociais estabelecidas em sociedades escravistas. No Brasil, principalmente após a Lei Eusébio de Queirós, de I850, que pôs fim ao tráfico internacional de escravizados africanos, desenvolveram-se formas precárias de trabalho com vistas a uma entrada do país no mundo do trabalho "livre" em consonância com as demandas de sistemas produtivos comprometidos com a lógica do trabalho dependente, como por exemplo, a escravidão. A Constituição republicana de I89I foi um dos marcos iniciais desse longo processo. Ainda assim, apesar da proliferação de contratos e de ajustes de trabalho "livre" e assalariado ocorrido no período, por vezes, tais relações de trabalho se aproximaram de situações servis. ${ }^{16} \mathrm{Ou}$ seja, as relações de trabalho, de hierarquias e de poder abrigaram identidades sociais senão idênticas, ao menos similares, àquelas que definiram as relações sociais na escravidão. Isto é, em muitos casos a liberdade não significou o avesso da escravidão. ${ }^{17}$

As propostas de criação de espaços para a mão de obra livre não incluíram um projeto deliberado de abandono do trabalho dependente. Houve nas décadas finais do XIX, em várias partes do Brasil, o aumento do emprego do trabalho escravo nas áreas de grande lavoura associada à mão de obra livre variada, arregimentada sob condições muito similares às restrições da escravidão.$^{18}$ Além disso, o período em tela foi marcado pela prática ilegal do tráfico internacional de escravizados africanos, que acarretou a

Is LIMA, H. E. "Sob o domínio da precariedade: escravidão e os significados da liberdade de trabalho no século XIX”. In: Topoi, vol. 6, n. II, p. 289-326, 2005. MENDONÇA, J. "Sobre cadeias e coerção: experiências de trabalho no Centro-Sul do Brasil do século XIX”. In: Revista Brasileira de História, vol. 32, n. 64, p. 45-6o, 2012.

I6 MATTOS, H. Prefácio. In: COOPER, F.; HOLT, T.; SCOTT, R. Além da escravidão: investigações sobre raça, trabalho e cidadania em sociedades pós-emancipação. Trad. Maria Beatriz de Medina. Rio de Janeiro: Civilização Brasileira, 2005, p. 13-38. MENDONÇA, J. “Sobre cadeias e coerção”, op. cit.

I7 Uma referência importante aqui é: HOLT, T. The problem of freedom: race, labor, and politics in Jamaica and Britain, 1832-1938. Baltimore: Johns Hopkins University Press, 1992. 


\section{REVISTA ANGELUS NOVUS}

difusão do costume de reduzir à escravidão pessoas livres, originando, por consequência, uma série de artifícios senhoriais cotidianos para dar aparência de legalidade à propriedade escrava adquirida de modo ilegítimo. Quer dizer, esse cenário foi definido pela precariedade da condição jurídica e social dos libertos e livres de cor e dos perigos da reescravização. ${ }^{19}$

Esse também foi o momento em que o escravismo, ou a instituição escravista, passou a sofrer uma profunda crise de legitimidade que, ao mesmo tempo, ocasionou e foi resultado do processo de constituição e expansão de um mercado de trabalho "livre”, impulsionado pelas grandes potências econômicas do período, destacadamente a Inglaterra. O movimento abolicionista e o processo de abolição surgiram, igualmente, nesse movimento. Tais eventos foram responsáveis, em grande parte, pela consolidação da formação de um mercado de trabalho "livre" no Brasil, mas que não alterou significativamente as formas das relações de trabalho no cotidiano dos trabalhadores. ${ }^{20}$

O debate sobre o trabalhador escravo também é um ponto fundamental que vem sendo discutido tanto pela historiografia da escravidão, quanto pela historiografia do trabalho. O historiador Cláudio Batalha, afirmou ser cada vez mais "necessário incluir [na história do trabalho] trabalhadores livres e não livres, urbanos e rurais, assalariados e autônomos, contratados e sazonais". ${ }^{21}$ Ainda assim, para o autor, são poucas as pesquisas que, em suas análises, avançaram no sentido de reconhecerem os escravizados como trabalhadores. Nessa perspectiva, ele questiona que, para além do princípio anunciado, "escravos e trabalhadores livres constituem uma única classe trabalhadora ou de fato são classes distintas, tanto em termos jurídicos (o que é óbvio), como em suas aspirações?”. ${ }^{22}$

Essa questão não constitui novidade na historiografia do trabalho. A tradicional história e sociologia do trabalho dos anos 1950 e 1960 consagrou a imagem do escravizado como não-trabalhador e sim como parte do sistema de produção, componente dos custos de fundação e conservação da plantation, juntamente com os

I8 OSÓRIO, H.; XAVIER, R. (Orgs.). Do tráfico ao pós-abolição: trabalho compulsório e livre e a luta por direitos sociais no Brasil. São Leopoldo: Oikos, 20I8. Um dos primeiros estudos a tratar desse tema para o caso brasileiro foi: EISENBERG, P. Modernização sem mudança: a indústria açucareira em Pernambuco, I840/ı91o. Trad. João Maia. Rio de Janeiro: Paz e Terra; Campinas: Editora da UNICAMP, 1977.

I9 CHALHOUB, S. A força da escravidão: ilegalidade e costume no Brasil oitocentista. São Paulo: Companhia das Letras, 20I2. MAMIGONIAN, B. Africanos livres: a abolição do tráfico de escravos no Brasil. São Paulo: Companhia das Letras, 2017.

20 LIBBY, D.; FURTADO, J. Trabalho livre, trabalho escravo: perspectivas de comparação. In: LIBBY, D.; FURTADO, J. (Orgs.). Trabalbo livre, trabalho escravo: Brasil e Europa, séculos XVII e XIX. São Paulo: Annablume, 2006, p. II-20.

2I BATALHA, C. “Os desafios atuais da história do trabalho”, op. cit., p. 89.

22 Idem, p. 92.

I22 • ano XI, n. 16, 2020 • ISSN 2179-5487 
animais, as máquinas e a sua manutenção. Apesar da intensa e criativa reavaliação desses campos de estudos, a questão do escravizado como um "não-trabalhador” permanece fortemente ratificada. ${ }^{23}$

A história da escravidão, por sua vez, seguiu caminho contrário. As experiências de vida e autonomia dos escravizados se tornaram objetos importantes de investigação tanto quanto os significados de liberdade, escravidão, família e trabalho, construídos por esses sujeitos. Neste aspecto, a influência de historiadores como Edward P. Thompson, Eugene Genovese e Herbert Gutman foi (e tem sido) fundamental para a continuada renovação desse campo de estudos. ${ }^{24}$ Em relação à história do trabalhador negro, as obras de Herbert Gutman - ainda pouco visitadas pela historiografia brasileira - despertam interesse tanto pela combinação de estudos sobre os trabalhadores escravizados e livres, quanto pelas contribuições inovadoras ao tema da cultura operária. ${ }^{25}$

Outro importante trabalho sobre o papel dos escravizados e da sua autonomia e agência em contextos de escravidão é "Era o escravo de plantação um proletário?" do antropólogo Sidney Mintz, estudo onde o autor complexificou as categorias trabalho e trabalhador-escravo. ${ }^{26}$ As perspectivas analíticas e os fundamentos teóricometodológicos adotados nesses trabalhos podem abrir um novo universo de possibilidades de investigações para a própria historiografia da escravidão, assim como para a história do trabalho.

A historiografia do trabalho também não se dedicou suficientemente ao estudo das relações raciais nos mundos do trabalho, algo que já foi longamente analisado pela história da escravidão. ${ }^{27}$ Ao longo do século XIX, principalmente a partir da década de

23 PRADO JÚNIOR, C. História econômica do Brasil. São Paulo: Brasiliense, I945, p. I69-I70. FERNANDES F. A integração do negro a sociedade de classes. São Paulo: EDUSP, 1964, vol. I, p. 38. Para um balanço da produção e dos debates sobre o tema nos anos I950-1960 ver: LARA, S. "Escravidão, cidadania e história do trabalho no Brasil", op. cit.

24 THOMPSON, E. A formação da classe operária inglesa, op. cit. GENOVESE, E. A terra prometida: o mundo que os escravos criaram. Trad. Maria Inês Rolim; Donaldson Magalhães Garschagen. Rio de Janeiro: Paz e Terra, 1988.

25 O historiador norte-americano Herbert Gutman escreveu o clássico: The black family in slavery and freedom: $1750-1925$. New York: Pantheon, 1976, obra importante na renovação da história do trabalho e dos trabalhadores negros nos EUA. Especialmente sobre a história do trabalho, suas principais publicações são: GUTMAN, H. Work, culture, and society in industrializing America: essays in american working-class and social history. New York: Vintage Books, 1977, e GUTMAN, H.; BERLIN, I. (Eds.). Power and culture: essays on the American working class. New York: New Press, 1987.

26 MINTZ, S. Era o escravo de plantação um proletário? In: MINTZ, S. O poder amargo do açúcar: produtores escravizados, consumidores proletarizados. Trad. Christine Rufino Dabat. Recife: Editora da UFPE, 2003, p. II7-I46.

27 MATTOS, H. Das cores do silêncio, op. cit. FRAGA FILHO, W. Encruzilhadas da liberdade: histórias de escravos e libertos na Bahia (1870-1910). Campinas: Editora da UNICAMP, 2006. LARA, S. H. Fragmentos 


\section{REVISTA ANGELUS NOVUS}

I850, a ideia de "raça" começou a aparecer como algo definidor da condição social de homens e mulheres de "cor". Nos anos I880, mas especialmente no pós-abolição, o Estado, as autoridades públicas e policiais, patrões e intelectuais ligados à imprensa recorreram mais intensamente aos marcadores raciais e de cor como critérios classificatórios dos “novos" cidadãos. Embora equiparados em sua condição civil, os sujeitos se diferenciavam segundo sua classificação racial. A concepção de raça era perfeita para quem pretendia reforçar e manter intactas as antigas hierarquias de poder. Com isso, o Estado e as elites dirigentes conseguiram formular e justificar novas políticas de controle e repressão não apenas sobre os que emergiram da escravidão, mas sobre toda a população "não-branca” e pobre. É nesse período que as novas políticas de exclusão racial começaram a se delinear. ${ }^{28}$

A questão da raça e, mais especificamente, da cor dos sujeitos é um ponto fundamental para se compreender a experiência dos trabalhadores negros nos mundos do trabalho, tanto durante o regime da escravidão, como em momentos posteriores. Diversos estudos da historiografia da escravidão têm demonstrado como as barreiras raciais dificultaram o acesso dos trabalhadores negros a melhores condições de vida e ampliação dos direitos de cidadania. ${ }^{29} \mathrm{O}$ associativismo negro pode ser uma interessante janela para se observar como raça, cor e racismo interferiram e ordenaram a vida de trabalhadores negros. A documentação produzida pelos espaços associativos de homens e mulheres de "cor" ainda vem sendo utilizada de maneira bastante tímida pela historiografia do trabalho. Documentos como atas, estatutos, jornais, literatura memorialística ao mostrar a existência de modelos organizativos, normas de conduta e códigos de valores próprios entre seus membros permite que analisemos mais detidamente as experiências dos homens e mulheres que os frequentavam. Isso, certamente, auxilia na ampliação dos temas, das abordagens e dos enfoques nos estudos históricos do trabalho.

$\mathrm{O}$ associativismo negro esteve presente desde o surgimento das primeiras práticas organizativas no século XVII, como as irmandades leigas e as corporações de ofícios. No século XIX, as associações poderiam ser marcadamente culturais, educativas, religiosas, sindicais, mutualistas ou abranger todas essas dimensões. As associações mutualistas, por exemplo, procuraram oferecer determinados benefícios, como o auxílio em casos de doença e funerais, bem como assistência médica e farmacêutica. Algumas foram criadas

setecentistas: escravidão, cultura e poder na América Portuguesa. São Paulo: Companhia das Letras, 2007.

28 ALBUQUERQUE, W. R. O jogo da dissimulação: abolição e cidadania negra no Brasil. São Paulo: Companhia das Letras, 2009, p. 3I-44.

29 Ver a já citada nota 3.

I24 • ano XI, n. I6, $2020 \cdot \mathrm{ISSN} 2 \mathrm{I} 79-5487$ 
por trabalhadores escravizados e seus descendentes, outras estiveram relacionadas aos trabalhadores livres de determinadas profissões, mais ou menos, especializadas. ${ }^{30}$

Determinadas associações de auxílio mútuo cumpriram um papel decisivo de valorização dos trabalhadores, através da "defesa do ofício e a instrução dos associados, quase sempre profissional (por meio de aulas e/ou bibliotecas)". ${ }^{31}$ Algumas delas ultrapassaram as iniciativas de suprir benefícios e pautaram reivindicações de categorias profissionais, desenvolvendo, assim, funções próprias dos sindicatos. Associações denominadas, à época, "resistências”, "ligas”, “coletivos” e termos afins possuíram, na maioria das vezes, funções sindicais que consistiam, por exemplo, na luta pela diminuição da jornada, por melhores salários e por condições mais dignas de trabalho. ${ }^{32}$

Uma questão central quando se trata do associativismo negro está relacionada aos interesses que moviam trabalhadores negros na criação, difusão e defesa desse tipo de organização. ${ }^{33}$ No seu estudo sobre os artífices negros recifenses, o historiador Marcelo Mac Cord afirmou que as associações mutuais dirigidas por aqueles sujeitos possibilitaram a valorização de experiências laborativas, bem como a formação de variadas identidades entre aqueles trabalhadores. ${ }^{34}$ A historiadora Beatriz Loner, em estudo sobre o movimento operário e os trabalhadores de duas cidades do Rio Grande do Sul, entre a segunda metade do século XIX e as primeiras décadas do século seguinte, asseverou que a constituição das práticas e espaços associativos dos trabalhadores negros ocorreu por duas razões:

30 A Sociedade de Beneficência Nação Conga Amiga da Consciência, por exemplo, foi fundada em 1872. CHALHOUB, S. Solidariedade e liberdade: sociedades beneficentes de negros e negras no Rio de Janeiro na segunda metade do século XIX. In: GOMES, F.; CUNHA, O. G. (Orgs.). Quase cidadão: histórias e antropologias do pós-emancipação no Brasil. Rio de Janeiro: Editora FGV, 2007, p. 23I. Já a Sociedade Cooperativa da Raça Negra, por sua vez, foi criada em I888. PINTO, A. F. M. Fortes laços em linhas rotas: literatos negros, racismo e cidadania na segunda metade do século XIX. 20I4. 326 f. Tese (Doutorado) Instituto de Filosofia e Ciências Humanas, Universidade Estadual de Campinas, Campinas, 20I4, p. 277.

BATALHA, C. "Relançando o debate sobre o mutualismo no Brasil: as relações entre corporações, irmandades, sociedades mutualistas de trabalhadores e sindicatos à luz da produção recente”. In: Revista Mundos do Trabalho, vol. 2, n. 4, p. 12-22, jan. 2010.

33 Os estudos sobre "mutualismo negro" ou sobre os trabalhadores negros engajados e inseridos nessa prática associativa têm crescido significativamente, alargando as pesquisas e evidenciando as potencialidades do debate. Alguns desses trabalhos são discutidos ao longo do texto, mas há outros que merecem referência, como: VITORINO, A. "Escravismo, proletários e as greves dos compositores tipográficos de I850 no Rio de Janeiro”. In: Cadernos AEL, vol. 6, n. Io/II, p. 69-I07, 1999. DUARTE, L. Pão e liberdade: uma história de escravos e livres na virada do século XIX. Rio de Janeiro: APERJ; FAPERJ; Mauad, 2002. SILVA JÚNIOR, A. "Escravidão, liberdade e cor nas sociedades de auxílios-mútuos (Rio Grande do Sul, I856-1914)". In: Anais do II Encontro Escravidão e Liberdade no Brasil Meridional, Porto Alegre, UFRGS, 2005. JESUS, R. P.; LACERDA, D. "Dinâmica associativa no século XIX: socorro mútuo e solidariedade entre livres e libertos no Rio de Janeiro Imperial”. In: Revista Mundos do Trabalbo, vol. 2, n. 4, p. I26-142, 2010. 


\section{REVISTA ANGELUS NOVUS}

Primeiro, a discriminação racial que enfrentaram na região e o fato de que logo se tornou evidente ao conjunto dos trabalhadores negros e suas lideranças, que sua inserção e a melhoria de condições de vida na sociedade brasileira estava condicionada a conquista de direitos para a classe operária, pois sua luta era coletiva e parte inseparável da luta do operariado brasileiro. ${ }^{35}$

A experiência constatada por Beatriz Loner também foi comum em outras regiões do Brasil. Em Campinas, por exemplo, nas décadas iniciais do século XX, algumas associações negras - Federação Paulista dos Homens de Cor (1903) e Liga Humanitária dos Homens de Cor (I915) - pautaram diversas bandeiras e propostas no seio das suas entidades, dentre elas, a defesa de questóes relacionadas ao mundo do trabalho, como o mutualismo e a construção de redes de relacionamentos com outras associações dos mundos dos trabalhadores. A criação e defesa dessa rede associativa estiveram ligadas à "relação de exploração vivida no ambiente de trabalho e a luta para limitar o campo de atuação do empregador nas relações trabalhistas, de acordo com as noções compartilhadas pelos trabalhadores, que só poderiam ser solucionadas caso se identificassem como pertencentes a uma mesma classe, se opondo aos interesses de outras”. Essa identificação “coletiva” entre os trabalhadores "poderia adotar diferentes meios para se definir, além de diversas estratégias de atuação, tais como, a adesão a associações reivindicatórias, mutualistas e recreativas, a participação em movimentos grevistas, associar-se a organizações administradas pela Igreja, estabelecer relações com profissionais liberais ou políticos, participar de eleições apoiando candidatos que aprovassem leis em prol dos trabalhadores". ${ }^{36}$ Isso não significou que questões raciais não fossem evocadas e pautadas nessas associações, inclusive, tanto Beatriz Loner, como Paula Nomelini, reconheceram o lugar das práticas e identidades raciais nas associações negras, contudo, em diversos momentos outras bandeiras foram levantadas, o que não significa, de modo algum, que essas coisas foram contraditórias, mas sim pautas que se relacionavam e conviviam no âmbito desses espaços associativos.

\section{Associativismo negro nos mundos do trabalho}

As análises das trajetórias das organizações, movimentos e manifestações dos trabalhadores negros levam à hipótese de que o associativismo negro, ${ }^{37}$ a partir da segunda metade do século XIX, comportou uma série de elementos fundamentais para

35 LONER, B. Construção de classe, op. cit., p. I7o.

36 NOMELINI, P. C. Associações operárias mutualistas e recreativas em Campinas (Igo6-1930). 2007. $230 \mathrm{f}$. Dissertação (Mestrado) - Instituto de Filosofia e Ciências Humanas, Universidade Estadual de Campinas, Campinas, 2007, p. 186.

I26 • ano XI, n. 16, 2020 • ISSN 2179-5487 
uma compreensão mais elaborada dos mundos do trabalho. Importantes estudos, como já mencionados trabalhos dos historiadores Beatriz Loner, Marcelo Badaró Mattos, Marcelo Mac Cord e outros, evidenciaram que as associações formadas por trabalhadores negros construíram e defenderam alguns propósitos fundamentais - a dignidade do trabalho, a respeitabilidade do trabalhador negro e a luta pela conquista da liberdade (que, em diversos contextos, significou também o combate ao preconceito de cor). A discussão racial, nesses espaços associativos, não se fazia sem referência à situação de classe dos trabalhadores. Quer dizer, o seu projeto político passava pelo reconhecimento dos critérios raciais e de classe que marcavam a sociedade brasileira. ${ }^{8}$ Portanto, é possível perceber que "raça” e "classe" estiveram entrelaçadas num jogo complexo. Assim, é possível pensar que, no bojo da formação de experiências coletivas, os trabalhadores negros organizados em espaços associativos se moveram na direção de construção de identidades classistas reconhecidas por um ideário comum - a valorização da imagem do trabalhador negro, a luta pela liberdade e o combate ao preconceito de cor, ou seja, nas associações negras o parâmetro raça foi lido como fundamento e não como recorte. Não foi apenas uma pauta identitária, mas sim o modus operandi que determinou as relações de poder e a organização das relações sociais.

Em vista disso, constatamos não ser possível, por exemplo, pesquisar a vida cotidiana e associativa dos trabalhadores negros deixando de lado questões relacionadas às suas múltiplas e complexas experiências, pois, uma associação constituída, em grande maioria por trabalhadores negros, por mais que se alinhasse aos interesses e propósitos de outras agremiações dos mundos dos trabalhadores, também pautava e propunha bandeiras voltadas para questões relacionadas às relações raciais. Os próprios termos que compunham os nomes de muitas dessas associações ("I3 de maio", "José do Patrocínio", "homens de cor", por exemplo) são um indicativo disso. Ainda assim,

37 O associativismo negro - entendido aqui como os espaços e práticas associativas construídas por diversos sujeitos e grupos da população negra e voltadas para os seus interesses e demandas, como os clubes culturais e recreativos, jornais, centros cívicos, grêmios literários, associações esportivas, beneficentes, mutualistas, operárias e irmandades leigas - foi um fenômeno social encontrado em diversas partes do Brasil entre segunda metade do século XIX e ao longo do XX. Ver por exemplo: RIBEIRO, J. R. "História social dos clubes negros no pós-abolição". In: Anais do $9^{\circ}$ Encontro Escravidão e Liberdade no Brasil Meridional, Universidade Federal de Santa Cataria, Florianópolis, 2018, p. I-I5.

38 MATTOS, M. B. Escravizados e livres, op. cit. LONER, B. Construção de classe, op. cit. MAC CORD, M. Artifices da cidadania, op. cit. O historiador João José Reis, em estudo pioneiro sobre os trabalhadores dos "cantos" em Salvador na segunda metade do século XIX, observou aspectos parecidos. Para ele, ao final da escravidão, esses trabalhadores passaram a ter uma tendência classista, ou seja, entre a identidade racial e étnica e a profissional, já predominava a segunda, "uma vez que a liberdade ajudou a nivelar, em alguma medida, trabalhadores que anteriormente se dividiam na rua entre libertos e escravos". REIS, J. J. "De olho no canto: trabalho de rua na Bahia nas vésperas da abolição”. In: Afro-Asia, n. 24, 200o, p. 240. Ver também o seu mais recente livro: REIS, J. J. Ganhadores: a greve negra de I857 na Bahia. São Paulo: Companhia das Letras, 2019. 


\section{REVISTA ANGELUS NOVUS}

interpretações superficiais e pouco atentas às experiências das associações e dos próprios trabalhadores negros marcaram as análises de vários dos estudos sobre associativismo de trabalhadores, que entre seus muitos méritos, por exemplo, está o de terem sidos pioneiros no uso da imprensa operária como fonte para o estudo do mundo associativo dos trabalhadores. Ao mesmo tempo em que trouxeram aspectos inovadores, estes estudos desconsideram a imprensa negra - e até mesmo os estatutos e atas de associações negras - como fontes, o que os levaram a excluir, ou integrar marginalmente, os trabalhadores negros e suas práticas associativas no debate historiográfico. Essas pesquisas, igualmente, não levaram em consideração as especificidades das propostas, bandeiras e açóes dos vários formatos organizativos dos mundos do trabalho, como a questão da origem nacional para as associações formadas majoritariamente por imigrantes, e o papel do racismo e do preconceito de cor para o associativismo negro.

Estudos importantes, como as já citadas pesquisas dos historiadores Beatriz Loner e Marcelo Mac Cord, têm evidenciado a importância do papel do preconceito de cor na constituição de espaços associativos negros. Contudo, a historiografia sobre o associativismo nos mundos dos trabalhadores pouco avançou no debate sobre o racismo e as práticas racializadas de discriminação e preconceito contra os sujeitos de cor, suas manifestações e seus espaços associativos. Compreender o papel do racismo e dos processos de racialização em curso na sociedade de então pode revelar os significados, interesses e intentos que moveram homens e mulheres negras na valorização, defesa e construção de espaços e identidades associativas:

Os fenômenos associativos negros, nesse sentido se colocam como importantes lócus de análise visto que permitem identificar práticas de sociabilidade hierarquizadas referendadas pelos seus membros, mas atualizadas pelas discussões políticas cotidianamente e, ainda questionar os significados políticos em jogo no contexto do pós-aboliçãa, assim como em que medida a escravidão e os problemas da liberdade sedimentavam as percepções que os sujeitos tinham dos lugares que ocupavam na sociedade. ${ }^{39}$

Isto é, a "raça” foi o fator determinante de organização dos negros em torno de um projeto comum de ação - mas isso não significou que questões raciais tenham sido o único critério definidor da (e na) fundação e existência das associações negras. Consideramos, assim, que o desafio dos estudos da historiografia do trabalho - e de outras correntes historiográficas interessadas no debate sobre a história do trabalhador negro - é localizar e matizar o lugar do "projeto negro" no âmbito destas associações de

39 SILVA, F. O. "A racialização observada pela ótica da experiência dos clubes e centros culturais negros na diáspora negra ao sul do Atlântico (Brasil-Uruguai): notas de pesquisa como forma de iluminar a nova história do trabalho". In: Revista Cadernos do LEPAARQ, vol. II, n. 22, 20I4, p. 530.

I28 • ano XI, n. I6, $2020 \bullet$ ISSN 2I79-5487 
trabalhadores. É algo mais complexo do que aparenta. Talvez, em torno da bandeira "operária” tenha existido projetos coletivos distintos sobre a inserção social dos negros no mundo do trabalho. Um desses projetos, certamente, foi a defesa de práticas positivas de construção de identidades, participação, reconhecimento e respeitabilidade social, assim como o debate e enfrentamento do preconceito de cor. Essa proposta foi encabeçada por algumas associações de trabalhadores negros, como foi o caso da Sociedade Protetora dos Desvalidos, uma das primeiras associaçóes civis negra criada no Brasil, fundada em Salvador em I851. Segundo o historiador Lucas Ribeiro Campos, "os sócios da entidade construíram um projeto político com a finalidade de atender às demandas dos trabalhadores livres de cor, nas últimas décadas do século XIX, como acesso à cidadania, educação e ajuda mútua". ${ }^{40}$

Resultado de uma cuidadosa pesquisa, o historiador Marcelo Badaró Mattos, em "Escravizados e livres", procurou recuperar o sentido profundo do processo do "fazerse" da classe trabalhadora na cidade do Rio de Janeiro, entre o fim do século XIX e início do seguinte. Fez a partir, principalmente, das "formas de organização que os trabalhadores - escravizados ou livres - construíram ao longo do tempo", com destaque para as trajetórias de "irmandades, associações de auxílio mútuo, sindicatos e partidos”. O livro mostrou como diversas práticas associativas dos trabalhadores, especialmente o associativismo negro e os seus mais variados desdobramentos, foram decisivos para a constituição do perfil da nova classe de trabalhadores assalariados, conforme destacou o autor:

Sem perder de vista a centralidade das organizaçôes tradicionalmente associadas à classe trabalhadora - o partido e o sindicato -, aqui se resgatou no recorte cronológico mais extenso formas organizativas mais antigas, que tiveram papel importante na construção das redes coletivas de solidariedade características da classe trabalhadora. Muitas vezes tais associações sobreviveram ao surgimento dos novos modelos associativos, conservando especificidade ou adaptando-se a novas situações. Mais uma vez, observou-se as combinações e os intercâmbios entre os modelos ao se discutir irmandades de operários com perfil nítido de mutualidade; associações mutuais assumindo um perfil de representação de interesses coletivos e inclusive organizando greves; e também organizações que assumiram a forma mutual, mas tinham por objetivo a luta pela liberdade dos escravizados, para os quais o limite legal do associativismo era o das irmandades. Partidos, ainda que assumindo uma identificação de classe - operária -, surgiram tendo por base muitos dos mesmos objetivos de valorização do trabalho e do trabalhador que já haviam animado o associativismo das ligas, corpos coletivos e outras entidades de base mutual. 


\section{REVISTA ANGELUS NOVUS}

Também os caminhos da generalização da forma sindicato como recurso organizativo central foram, por tudo isso, mais complexos do que poderia parecer à primeira vista. ${ }^{41}$

O estudo clássico de Maria Cecília Velasco e Cruz sobre os portuários do Rio de Janeiro na virada do século XIX para o XX, também demonstrou a existência de um forte elo entre as formas de organização dos trabalhadores escravizados e a formação e organização da Sociedade de Resistência dos Trabalhadores em Trapiche e Café, conhecida popularmente por "Resistência", criada em 1904, pelos trabalhadores portuários, com grande destaque e presença dos trabalhadores negros. Segundo Velasco e Cruz, a forte "linha de continuidade entre os escravos e libertos dos velhos tempos imperiais e os proletários da Primeira República”, ajudaram a formatar e redesenhar as redes de sociabilidade, solidariedade e controle de um mercado de trabalho construídas ainda nos tempos da escravidão e que tiveram papel fundamental na garantia $e$ privilégio dos trabalhadores negros nos mundos do trabalho do porto carioca. ${ }^{42}$

A historiadora Erika Bastos Arantes, por sua vez, analisando também o caso dos trabalhadores do porto do Rio de Janeiro nas primeiras décadas republicanas, observou como as suas outras formas de organização, mais especificamente, as de cunho recreativo, como as sociedades carnavalescas, os clubes dançantes, ranchos, entre outras, contribuíram de alguma forma para que os trabalhadores se identificassem como parte de um mesmo mundo e se reconhecessem como trabalhadores. Em linhas gerais, Arantes procurou demonstrar a "diversidade associativa" daqueles sujeitos, chamando a atenção para o fato de que "identidades múltiplas - percebidas na diversidade das organizações - não impediam uma identidade de classe”:

Os integrantes das associações recreativas ao fazerem do lazer um motivo de união, mostravam ter ali um elemento de identidade, formando laços que eram expressos em momentos diversos. Os membros dos sindicatos portuários, ao se reunirem para festejar o carnaval, organizar ranchos ou simplesmente se encontrarem em bailes e festas, mostram que os laços que os uniam iam além daqueles construídos durante o trabalho e nas assembleias sindicais. Se, por um lado eles se reuniam para discutir os rumos da greve, a jornada de trabalho ou o preço dos volumes das sacas de café que embarcavam diariamente no cais do porto, por outro também se reuniam para resolver o dia apropriado para sair o rancho, quando haveria baile nas sedes dos clubes recreativos e outras questôes relativas ao

4I MATTOS, M. B. Escravizados e livres, op. cit., p. 32, 83-I40, 226-227.

42 CRUZ, M. C. V. Virando o jogo, op. cit. Um dos primeiros trabalhos a abordar a experiência da Sociedade de Resistência dos Trabalhadores em Trapiche e Café e os seus membros foi: ALBUQUERQUE, M. B. M. Trabalbo e conflito no porto do Rio de Janeiro (I904-1920). 1983.305 f. Dissertação (Mestrado) - Instituto de Filosofia e Ciências Sociais - Universidade Federal do Rio de Janeiro, Rio de Janeiro, 1983. Consultar também: GALvão, O. M. R. A Sociedade de Resistência ou Companbia dos Pretos: um estudo de caso entre os arrumadores do porto do Rio de Janeiro. 1994. 64 f. Dissertação (Mestrado) - Instituto de Filosofia e Ciências Sociais - Universidade Federal do Rio de Janeiro, Rio de Janeiro, 1994.

I30 • ano XI, n. I6, $2020 \bullet$ ISSN 2179-5487 
seu lazer. E, nesses momentos, assim como no trabalho e no sindicato, eles também se reconheciam como fazendo parte de um mesmo grupo, com interesses semelhantes, se identificando como trabalhadores. ${ }^{43}$

\section{Palavras finais}

Redimensionar os significados do associativismo negro, no contexto da formação de racionalidades do trabalho livre, associado à emergência de discursos sobre a modernização nacional diante do desmonte estrutural da escravidão, e ao recrudescimento do racismo, pode contribuir para a avaliação do papel ocupado pelos trabalhadores negros nos mundos do trabalho durante as últimas décadas da escravidão e no pós-abolição. Também é importante ter em conta que as experiências dos trabalhadores negros no Brasil do século XIX podem oferecer paralelos para a compreensão das trajetórias de outros trabalhadores, da história do trabalho e do movimento operário em outras partes do Atlântico, estabelecendo conexões ou comparações entre regióes e realidades aparentemente díspares. Além disso, as transformações vivenciadas pela sociedade brasileira (formação de um mercado de trabalho livre, processo de abolição, urbanização e industrialização, crescimento demográfico) tiveram relações diretas com o desenrolar de processos históricos mais amplos, ocorridos além das fronteiras nacionais e comuns ao que se pode denominar, genericamente, de emergência da chamada modernidade capitalista no mundo. ${ }^{44}$

43 ARANTES, E. B. "A estiva se diverte: organizações recreativas dos trabalhadores do porto carioca nas primeiras décadas do século XX”. In: Tempo, vol. 21, n. 37, 2015, p. 40-4I. Ver também: ARANTES, E. B. O porto negro: cultura e associativismo dos trabalhadores portuários no Rio de Janeiro na virada do XIX para o XX. 20IO. 223 f. Tese (Doutorado) - Instituto de Ciências Humanas e Filosofia, Universidade Federal Fluminense, Niterói, 20I0.

44 TOMICH, D. Pelo prisma da escravidão: trabalho, capital e economia mundial. Trad. Antônio de Pádua Danesi. São Paulo: EDUSP, 2oII. Ver também: TOMICH, D. "Trabalho escravo e trabalho livre: origens históricas do capital”. In: Revista USP, n. I3, p. Ioo-I17, 1992. 